Estudioso incansable, periodista de opinión, no sólo concibió y analizó las posibilidades de reforma del sector salud tanto de su país como del conjunto de América Latina, sino que se convirtió en uno de los más importantes implantadores de novedosos planes y programas para garantizar el acceso de la población pobre a más y mejores servicios de salud.

Al inicio de los años noventa se desempeñó como Ministro de Salud en el gobierno del Presidente César Gaviria. También fue Subjefe del Departamento Nacional de Planeación, miembro de la Comisión para la Modernización del Estado y responsable del equipo que preparó el Plan Nacional de Desarrollo 19911994, además de otras importantes responsabilidades ligadas con la salud y el sector social en general. Participó en el diseño de la Ley 60, que reformó el Sistema Nacional de Salud de Colombia, en la instauración del proceso del sistema público de salud en más de $50 \%$ del territorio colombiano, y en la importantísima Reforma de Seguridad Social (Ley 100).

El entusiasmo y la participación del doctor Londoño fueron elementos clave para la creación y funcionamiento de una red de investigación, análisis y difusión de temas seleccionados con la inaplazable reforma del Sector Salud de los países de América Latina y el Caribe.

En 2002, al iniciar el gobierno del Presidente Alvaro Uribe, le fue encargada la responsabilidad del nuevo Ministerio de Protección Social, el cual combina las áreas de competencia de los ministerios de Salud y Trabajo, con el objetivo de coordinar estos importantes sectores de la política social en aras del mejoramiento de la calidad de vida para la población colombiana.

Juan Luis Londoño será recordado fundamentalmente como un reformador social, una persona con visión extraordinaria, que supo adelantarse a sus tiempos. Su juventud no le impidió ser justamente un visionario, un pionero.

\section{Acuerdo en torno a un tratado internacional para el control del tabaco}

"Un importante paso adelante para la salud de los pueblos y las naciones".

\section{Dra. Gro Harlem Brundtland}

Con el objetivo de contender contra la epidemia del tabaquismo, 171 estados miembros de la Organización Mundial de la Salud (OMS) acordaron, en Ginebra, el 1 de marzo de 2003, transmitir a la Asamblea Mundial de la Salud un tratado en materia de salud pública sobre el control de la oferta y del consumo de tabaco. Por considerarlo del interés de los lectores de Salud Pública de México reproducimos fragmentos del texto preliminar del Convenio marco de la OMS para el control del Tabaco ${ }^{1}$.

Impuestos. El texto reconoce formalmente que las medidas relacionadas con los precios y los impuestos son un mecanismo importante para reducir el consumo de tabaco, en particular entre los jóvenes, y exige a los signatarios que piensen en los objetivos de salud pública al aplicar las políticas relacionadas con los impuestos y los precios de los productos de tabaco.

Etiquetado. El texto exige que al menos $30 \%$, pero preferiblemente $50 \%$ o más, de la superficie expuesta en los envases de los productos de tabaco esté ocupada por advertencias sanitarias claras en forma de texto, imágenes o una combinación de ambos. Los requisitos en cuanto al envasado y el etiquetado también prohíben usar términos confusos que den la falsa impresión de que un producto es menos nocivo que otros, a veces mediante expresiones como "ligero", "suave" o "con bajo contenido de alquitrán".

Publicidad. Si bien todos los países estaban de acuerdo en que la prohibición total de ésta tendría un importante efecto de reducción del consumo de productos de tabaco, en algunos existen disposiciones constitucionales -por ejemplo las relativas a la libertad de expresión con fines comerciales- que no les permitirán imponer una prohibición completa en todos los medios. En el texto final se pide a las partes que procuren hacer progresos para conseguir una prohibición completa en el término de los cinco años siguientes a la entrada en vigor del Convenio. También se incluyen disposiciones para los países que no puedan imponer una prohibición completa, con el fin de que restrinjan la publicidad, la promoción y el patrocinio del tabaco dentro de los límites que marque su legislación.

En el texto se pide explícitamente a los futuros signatarios del Convenio que estudien la posibilidad de preparar un protocolo que aborde con mayor detalle la publicidad transfronteriza. Este podría incluir los aspectos técnicos de las medidas que permitirían impedir o bloquear la publicidad en medios tales como la televisión por satélite o Internet.

Responsabilidad. Se alienta a las Partes en el Convenio a emprender acciones legislativas para responsabilizar a la industria tabacalera de los costos asociados con el consumo de tabaco.

Financiamiento. Se estipula que las Partes proporcionarán apoyo financiero a sus programas nacionales de control del tabaco. Además, en el texto se alienta a usar y promover los fondos de desarrollo existentes para el control del tabaco. Varios países y organismos de desarrollo se han 
comprometido ya a incluir el control del tabaco entre las prioridades de desarrollo.

En el texto se estipula también que los países promoverán programas de tratamiento que ayuden a las personas a dejar de fumar, y programas de educación que eviten la adquisición del hábito, que prohibirán la venta de productos de tabaco a los menores, y que limitarán la exposición del público al humo ajeno.

Los elementos del tratado reflejan las políticas de la OMS y del Banco Mundial orientadas a un plan integral de reducción del consumo de tabaco. Aunque la Asamblea Mundial de la Salud ha adoptado ya, desde 1970, cerca de 20 resoluciones en apoyo del control del tabaco, la diferencia respecto de este convenio es que las obligaciones de este tratado serán jurídicamente vinculantes para las Partes en el Convenio una vez que éste entre en vigor.

\section{REFERENCIAS}

1. 0 rganización Mundial de la Salud. Acuerdo en torno a un tratado internacional para el control del tabaco. Ginebra: O MS, 2003. Disponible en: http://www.who.int/mediacentre/releases/2003/ pr21/es/index.html. consultada el 3 de abril de 2003.

\section{Un nuevo reto para la salud pública: el síndrome respiratorio agudo severo}

El síndrome respiratorio agudo severo (SIRAS) o severe acute respiratory syndrome (SARS), es una condición de origen probablemente viral que ha sido identificado recientemente en pacientes en Asia, América del Norte y Europa. Entre el 1 de febrero y el 30 de marzo de 2003, el SIRAS había sido diagnosticado en más de 1800 pacientes, en 17 países, con un total de 62 defunciones. ${ }^{1}$
De acuerdo con la definición de la Organización Mundial de la Salud (OMS), un caso sospechoso de SIRAS en una persona se identifica documentando fiebre $\left(\geq 38^{\circ} \mathrm{C}\right)$, síntomas de las vías respiratorias inferiores y contacto con una persona que haya padecido SIRAS o evidencia de que haya viajado a alguna de las áreas en donde se ha documentado la transmisión de la enfermedad. Un caso probable incluye, además, datos de neumonía en la radiografía de tórax, síndrome de dificultad respiratoria aguda (SDRA) o una enfermedad respiratoria inexplicable que desencadene la muerte y que en los datos de autopsia muestre evidencia patológica de SDRA. ${ }^{2}$

La enfermedad, reportada por primera vez en el otoño de 2002 en la Provincia de Guangdong, en el sur de China, se propaga rápidamente pero no es uniformemente contagiosa. La mayoría de los casos se han presentado en Hong Kong en donde la epidemia continúa expandiéndose a pesar de los esfuerzos por parte del gobierno para contenerla. La mayoría de los casos se presenta en personal de hospitales y contactos cercanos de los enfermos. La mortalidad se asocia principalmente a pacientes con algún tipo de susceptibilidad como diabetes tipo 2 y enfermedad pulmonar crónica. Los casos conglomerados en comunidades instaladas en hoteles o edificios de apartamentos han demostrado que es muy contagiosa a través del contacto cercano y prolongado con pacientes enfermos. Se ha confirmado que durante el periodo de incubación de la enfermedad -que parece ser de entre 1 a 11 días, con una media de cinco díaslos pacientes pueden transmitirla a través de las gotitas de saliva y, probablemente, también por sistemas de conducción de aire.$^{3}$

La sintomatología clínica inicial de los casos que se han presentado incluyen fiebre $\geq 38^{\circ} \mathrm{C}$ por más de 24 horas, tos no productiva, disnea (entre 3 y 7 días después del inicio de la fiebre), malestar, mialgias y dolor de cabeza. Al examen físico se puede observar dolor torácico, taquicardia, taquipnea y presión arterial baja. Fuera del sistema respiratorio, el examen físico es normal. Las radiografías de tórax revelan alteraciones en las zonas basales pulmonares, incluyendo un patrón intersticial reticular que posteriormente se transforma en una opacidad homogénea. Las pruebas de laboratorio muestran linfopenia, niveles elevados de lactato deshidrogenasa, aminotransferasa de aspartato y creatinin-cinasa. En algunos casos se demuestran trombocitopenia y leucopenia. ${ }^{3,4}$

Los análisis microbiológicos en los que se han incluido cultivo de tejidos, microscopia electrónica, tecnología de microarreglos, inmunofluorescencia indirecta y la reacción de la polimerasa en cadena $(\mathrm{PCR})$, señalan que un nuevo coronavirus es el principal sospechoso en la búsqueda de la causa del SIRAS, aunque falta por confirmarse si es el único causante de la enfermedad. Investigadores de la Universidad de Hong Kong han anunciado el desarrollo de una prueba diagnóstica basada en PCR para la identificación rápida del virus, la cual se encuentra en evaluación para su empleo a escala mundial. Asimismo, los esfuerzos por desarrollar una vacuna a corto plazo ya se han iniciado. ${ }^{1}$

Respecto al tratamiento, se han probado numerosas terapias antimicrobianas, pero sin claros efectos. Sin embargo, considerando la posibilidad de la etiología viral del SIRAS, se recomienda el empleo empírico de un agente antiviral como la ribavirina que es un análogo ribonucleótido que induce mutagénesis letal en los virus con genoma de RNA como los metaneumovirus y los coronavirus. Este medica- 